\title{
ROLE OF COMBINED KETOCONAZOLE AND TAMSULOSIN IN SUCCESSFUL TRIAL OF VOIDING WITHOUT CATHETER (TWOC) IN PATIENTS WITH ACUTE URINARY RETENTION DUE TO BENIGN PROSTATIC OBSTRUCTION
}

\author{
Muhammad Asim, Syed Farhan Ahmed*, Muhammad Sajid Ali*, Imran Memon*, Waqas Memon*, Muhammad Rashid*, \\ Kiran Abbas**, Moiz Ahmed** \\ Dow University of Health Sciences, Karachi Pakistan, *Liaquat National Hospital and Medical College, Karachi Pakistan, **Jinnah \\ Postgraduate Medical Center, Karachi Pakistan,
}

\begin{abstract}
Objective: To compare the frequency of patients with successful trial of voiding without catheter after acute urinary retention secondary to benign prostatic hyperplasia in patients taking ketoconazole and tamsulosin vs tamsulosin alone.

Study Design: A quasi-experimental study.

Place and Duration of Study: Urology Ward, Liaquat National Hospital, Pakistan, from Jul 2016 to Jan 2017. Methodology: A total of 162 patients presenting with acute urinary retention were divided into two groups. Group A received tamsulosin $0.4 \mathrm{mg}$ OD and ketoconazole $200 \mathrm{mg}$ while group B received tamsulosin and placebo. Trial of voiding without a catheter was induced after one week of medication.

Results: In group-A, $69(85.2 \%)$ of patients were able to void as compared to group B, where only $60(74.1 \%)$ of patients were able to void ( $p=0.05)$. Successful trial of voiding without catheter was observed in $64(79 \%)$ and 49 $(60.5 \%)$ in patients of group-A and group-B respectively. The association of successful trial of voiding without catheter with the two study groups was found significant $(p=0.010)$.

Conclusion: Trial of voiding without catheter in men catheterized for acute urinary retention due to benign prostatic hyperplasia was significantly more successful if treated in combination of ketoconazole and tamsulosin as compared to tamsulosin only.

Keywords: Acute urinary retention, Benign prostatic hyperplasia, Ketoconazole, Tamsulosin, Trial without Catheter.

This is an Open Access article distributed under the terms of the Creative Commons Attribution License (http://creativecommons.org/licenses/by/4.0), which permits unrestricted use, distribution, and reproduction in any medium, provided the original work is properly cited.
\end{abstract}

\section{INTRODUCTION}

Acute urinary retention (AUR) due to benign prostatic enlargement is a common urological emergency and an important cause of morbidity. Nearly $24 \%$ of the hospital urologic emergencies are affected by AUR1. However BPH accounts for more than $75 \%$ of cases in men over 70 years. The age related morbidity over one year ranges from $4.1 \%$ in $45-54$ years to $32.8 \%$ from those above 85 years of age ${ }^{2}$. A large cohort based studies, on California men, found increasing incidence among Asians, and Hispanics ${ }^{3}$. In Pakistan, there were $78.3 \%$ cases of AUR reported in 345 patients of $\mathrm{BPH}^{4}$.

Due to increasing morbidity associated with

Correspondence: Dr Kiran Abbas, E-7 Dolmen Courts, Gulistane-Johar, Block-13, Karachi Pakistan

Received: 27 Feb 2020; revised received: 22 Apr 2020; accepted: 14 May 2020 the conventional management of the AUR secondary to benign prostatic enlargement has led to trial of voiding without catheter (TWOC) approach and has made this popular. TWOC has become the standard protocol for AUR and benign prostatic enlargement ${ }^{5}$. This procedure involves removal of bladder catheter after 1 week of alpha1 blockage permitting $23-40 \%$ of patients to effectively void and delay surgical treatment if required, thus avoiding the need for prolonged catheterization and risk of sepsis, and need for hospitalization. A Cochrane Meta-analysis in 2009, found alpha blockers to increase success rates of TWOC when compared with placebo ${ }^{6}$. Alpha-1 blocker acts by inhibiting the alpha- 1 receptors in smooth muscles, which results in the relaxation of the prostatic and bladder neck smooth muscles ${ }^{7}$. Although rate of successful TWOC improve significantly with the use of alpha-1 blocker, still there 
is enough space available for further improvement.

Prostatic growth depends on a critical level of androgen and its deprivation subsequently leading to atrophy of prostatic gland ${ }^{8}$. Ketoconazole is a synthetic antifungal and is known to cease synthesis of testosterone by inhibiting the hydroxylation of cytochrome P450, which is reversible 9,10 .

Currently, there has been no such study conducted in Asian population subjects which are different from Caucasian, European and American due to geographic and environmental factors. Therefore we aimed our study to determine the effectiveness of combined treatment of ketoconazole and tamsulosin over single drug tamsulosin in treatment of AUR secondary to benign prostatic enlargement in Pakistani population, so that superior of the two treatment modalities could be used and advocated in future in such cases.

\section{METHODOLOGY}

It was a quasi-experimental study conducted at 40-bedded urology ward at Liaquat National Hospital, Karachi from July 2016 to January 2017 for a period of six months. Since the prevalence of prostatic disorders was not, a total of 169 patients were recruited for the study. The sample size was calculated using Openepi calculator for casecontrol study. Based on the previous study, the frequency of cases and controls were 35 (58.3\%) and 18 (30\%) respectively; with an effect size of 19, that voided successfully. The sample sized obtained was $110^{11}$. The sample was recruited through non-probability consecutive sampling technique. To minimize the bias, the present study used the single blinded design, where only the principal investigator knew which interven-tion is being given to each participant.

Data was collected from patients of AUR secondary to obstruction admitted through emergency in Urology unit at Liaquat National Hospital, who underwent foley's catheterization. All the patients between the ages of 60 to 80 years ${ }^{2}$, presented with acute urinary retention as defined by the inability to voluntarily pass urine despite having a full bladder detected on ultrasound examination secondary to benign prostatic enlargement were enrolled in our study. Patients with major illness like prostate cancer, neurological, chronic renal and/or hepatic insufficiency were excluded from the study. Patients with known hypersensitivity to drugs (i.e; tamsulosin or ketoconazole), those who have recurrence of AUR, patients of diabetes, patients with a history of spinal trauma, active urinary tract infection and urolithiasis. Urethral stricture and calculi were exluded with the help of ultrasound and KUB x-ray.

Informed written consent was taken from the patient by the researcher prior to the data collection. All patients were informed of the purpose, procedure steps, any adverse effects and complications they might experience during the study. Permission from the institutional ethics committee (App \# 0168-2015 LNH-ERC) was also taken before starting study. Patients of group A received tamsulosin $0.4 \mathrm{mg}$ OD and ketoconazole 200mg TDS and patients of group B received tamsulosin $0.4 \mathrm{mg}$ and placebo. All drugs were given orally. All patients underwent clinical examination and laboratory investigations including complete blood count (CBC), Urea and Creatinine, Urinalysis, culture, and ultrasound bladder and prostate. TWOC was given after 1 week of medication and the patient was admitted for 24 hours and observed for retention as per standard protocol. TWOC was considered successful if the patient was able to void and post void was $<1 / 3$ of the pre void on ultrasound examination.

Data was entered by double entry method and analyzed by statistical software package SPSS version 20.0. Mean \pm SD was calculated for quantitative variables like age of patient, duration of retention, prostate size. Frequency and percentage was computed for qualitative variable i.e. successful TWOC after treatment. Chi square test was used to collate significant differences between groups. The $p$-value $\leq 0.05$ was considered significant. Confounding variables were controlled with the help of exclusion criteria. 


\section{RESULTS}

Total 162 male patients who were presented with acute urinary retention secondary to benign prostatic enlargement were included in the study and equally but randomly divided in two treatment groups i.e. group-A: Tamsulosin and Ketoconazole and group-B: Tamsulosin And Placebo to determine the frequency of patients with successful TWOC between two groups.

The detailed descriptive statistics of both groups according to age, duration of retention and prostate size were presented in table-I.

Table-I: Descriptive statistics of the study group.

\begin{tabular}{l|c|c}
\hline Parameter & $\begin{array}{c}\text { Group A } \\
\text { (Intervention) }\end{array}$ & $\begin{array}{c}\text { Group B } \\
\text { (Control) }\end{array}$ \\
\hline $\begin{array}{l}\text { Mean Age } \pm \text { SD } \\
\text { (years) }\end{array}$ & $69.95 \pm 6.05$ & $70.04 \pm 5.97$ \\
\hline $\begin{array}{l}\text { Mean Duration } \pm \text { SD } \\
\text { of retention (days) }\end{array}$ & $1.57 \pm 0.51$ & $1.56 \pm 0.61$ \\
\hline $\begin{array}{l}\text { Mean Prostate size } \pm \\
\text { SD (grams) }\end{array}$ & $39.07 \pm 6.09$ & $39.60 \pm 5.85$ \\
\hline
\end{tabular}

Table-II: Comparison of study outcomes between group A and group B.

\begin{tabular}{l|c|c|c}
\hline Parameter & $\begin{array}{c}\text { Group A } \\
\text { n (\%) }\end{array}$ & $\begin{array}{c}\text { Group B } \\
\text { n (\%) }\end{array}$ & $\begin{array}{c}p \text { - } \\
\text { value }\end{array}$ \\
\hline $\begin{array}{l}\text { Patients able to } \\
\text { void }\end{array}$ & $69(85.2 \%)$ & $60(74.1 \%)$ & 0.100 \\
\hline $\begin{array}{l}\text { Post void } \\
\text { residual urine } \\
\text { volume of <1/3 } \\
\text { on ultrasound }\end{array}$ & $64(79.0 \%)$ & $49(60.5 \%)$ & 0.01 \\
\hline $\begin{array}{l}\text { Successful trial } \\
\text { of voiding } \\
\text { without catheter }\end{array}$ & $64(79.0 \%)$ & $49(60.5 \%)$ & 0.010 \\
\hline
\end{tabular}

Results showed that in group-A, $69(85.2 \%)$ of patients were able to void and in group-B, 60 $(74.1 \%)$ patients were able to void $(p=0.1)$. It was observed that among patients of group-A, post void residual urine volume was found $<1 / 3$ on ultrasound in $64(79.0 \%)$ patients, and in group-B this was found in $49(60.5 \%)$ patients with a $p$-value of $<0.001$.

The final outcome i.e. successful trial of voiding without catheter was observed in $64(79.0 \%)$ and $49(60.5 \%)$ patients in group A and group-B respectively. The results showed that association of successful TWOC with the two study groups was found significant $(p=0.010)$, details are shown in table-II.

Both ketoconazole and tamsulosin were well tolerated among study participants. The most frequent side effect with tamsolusin plus ketoconazole was dizziness and headache which was statistically insignificant.

\section{DISCUSSION}

Acute urinary retention (AUR) is a frequent urological emergency characterized by a sudden and excruciating failure to pass urine. The frequency of this complication in patients with benign prostatic hyperplasia varies broadly from 0.4 to $25 \%$ in men seen in urology practices ${ }^{12}$. Prompt treatment comprises of bladder decompression, usually by a urethral catheter. Previously, surgery was the only available treatment and management option for such cases and subsequently prolonged catheterization was associated with high mortality and morbidity among these patients. The high complication rate resulted in increased frequency of using trial without catheter as a means to reduce catheter-related complications postoperatively. This includes catheter expulsion after one to three days, permitting the patient to void in $23-40 \%$ of cases ${ }^{13,14}$.

We reported a rate of $79 \%$ for successful trial of voiding without catheter in patients given a combination of ketoconazole and Tamsulosin, which was significantly higher $(p=0.01)$ than patients who were on Tamsulosin only regimen with a rate of $60.5 \%$ for successful trial. Our study findings are in accordance with a recent study by Elbendary et al. who observed the dramatically significant benefit in successful trial achieved when a combination of Ketoconazole and Tamsulosin were used compared to Tamsulosin alone $(77.35 \% \text { vs. } 58.84 \%)^{15}$.

The benefit of utilizing trial of void without catheter is that it allows the surgical procedures related to benign prostatic hyperplasia to be executed later, and without the further risks of catheter-related complications perioperatively. The practice of trial of voiding without catheter 
was in accordance with a 2004 national survey conducted among 410 expert urologists by Manikandan et al 16 , revealing that in 73.9 percent cases, TWOC was a part of their regular practice, mostly after 2 days of catheterization (48.5\%), they used TWOC. It has been reported that probabilities of effective TWOC increase with the duration of catheterization ${ }^{17}$. A study even reported that catheterization for $>3$ days was associated with a greater TWOC success rates ${ }^{5}$.

In this study, the mean age of the patient in the interventional group was $69.95 \pm 6.05$ years while it was $70.04 \pm 5.97$ in the control group $(p=0.226)$ which was comparable to that stated in different studies $18-20$. Contrary to the findings of Djavan et al19, the distinction of age between those who voided effectively and those who did not, used to be no longer statistically significant $(p>0.05)$. These findings were in correspondence with those explained by Reynard and his team ${ }^{20}$. In similarity to the above mentioned studies, the difference of age between the two groups in the present study was not significant $(p=0.226)$ to the final outcome of successful trial of voiding without catheter.

Tamsulosin (in $0.4 \mathrm{mg}$ once every day dosage) are way better endured due to the low risk of postural hypotension, eliminating dose titration ${ }^{21}$. Nordling et al, and Dunn et al, had too affirmed that the advantage to risk profile of these two drugs seems to be decreased with higher dosage 22,23. Our study was in accordance with a study by McNeill et al, who reported that TWOC was effective with tamsulosin with a success rate of $70 \%{ }^{24}$. In our study this rate was $60.5 \%$ which is more or less comparable. In another study, a combination of ketoconazole with tamsulosin in patients with AUR due to $\mathrm{BPH}$ was taken. This presumption was related partially to the quick and productive antiandrogenic properties of ketoconazole and in part to the prostate itself because it is an androgendependent organ ${ }^{10}$.

The pathogens is behind acute urinary retention is the unexpected rise in the bladder outlet obstruction with resulting detrusor muscle malfunction. Subsequently, tamsulosin and other alpha blockers have been shown to increase the positive outcome of TWOC in these cases ${ }^{24}$. Nevertheless, these drugs solely have an effect on the dynamic part of this obstruction. However, because of the administration of ketoconazole, there is a rapid fall in testosterone level in the body, resulting in decreased edema and vascularity of the prostate subsequently improving the static part of the obstruction. These speculations are reinforced by the well-known impact of androgen deficiency on the prostate as discussed earlier ${ }^{8}$ and by means of slight decrease in the prostate size that was mentioned in this study after ketoconazole administration ${ }^{15}$.

It has been observed that the older age, larger prostate size, large volume drained at catheterization, and spontaneous acute urinary retention increases the chances of TWOC failure5. Djavan et al 19 , reported that the a better outcome with TWOC can be achieved if the catheter is retained for 7 days. On the other hand, contrasting evidence suggests some physicians retain catheters for approximately 47 days ${ }^{16}$. Interestingly, a study by Fitzpatrick et al ${ }^{5}$ revealed that catheterization for 43 days does not affect the success rate for TWOC success. Nevertheless it has been noted to increase unfavourable outcomes as there is an increased risk of lower urinary infections, stenosis, hematuria and other catheter-related complications. In the current trial, we placed the catheter for seven days to optimize the chance for the drug to work ${ }^{15}$.

The principal limitations of this study are the unavailability of the double placebo control group and the deficiency of data about the modifications in each of the testosterone level and the histopathological findings after ketoconazole administration. The present study includes a single-center experience, nonrandomized study design. One of the impediments of this study is that it was performed with a small sample size; the outcomes might not be generalizable to larger populations. 


\section{CONCLUSION}

Our study concluded that TWOC in men catheterized for AUR was significantly more successful if treated in combination of ketoconazole and tamsulosinin patients compared to tamsulosin only.

\section{CONFLICT OF INTEREST}

This study has no conflict of interest to be declared by any author.

\section{REFERENCES}

1. Ludvigson AE, Beaule LT. Urologic emergencies. Surg Clin N Am 2016; 96(3): 407-24.

2. Ryan P, Ryan É, Keenan R, Haroon U, Broe M, Forde J, et al. Admission of patients with acute urinary retention leads to a definitive management decision. Ir J Med Sci 2019; 1(1): 1-5.

3. Meng F, Zhou L, Zhao Y. Clinical nursing of indwelling catheter for patients with benign prostatic hyperplasia complicated with acute urinary retention. In 2nd symposium on health and education 2019 (SOHE 2019) 2019 May. Atlantis Press.

4. Addepalli J, Balasubramanya KS, Francis JM, Thanneru K. A study on acute urinary retention in patients with benign prostatic hyperplasia at a rural setup. Int J Surg 2019; 6(5): 1772-76.

5. Kresevic DM, Dolinar T, Early A, Burant CJ. Patterns of benign prostatic hyperplasia associated urinary retention: indwelling urinary catheter use and clinical sequelae. Urol Pract 2016; 3(2): $118-23$.

6. Zeif HJ, Subramonian K. Alpha blockers prior to removal of a catheter for acute urinary retention in adult men. Cochrane Database Syst Rev 2009; 7(4): CD006744.

7. Huang LK, Chang YH, Shao I, Lee TL, Hsieh ML. Clinical outcome of immediate transurethral surgery for benign prostate obstruction patients with acute urinary retention: more radical resection resulted in better voiding function. J Clin Med 2019; 8(9): 1278.

8. Showalter VC, Raynor MC. Medical management of benign prostatic hyperplasia. inprostatic artery embolization 2020 (pp. 21-42). Springer, Cham.

9. Patel V, Liaw B, Oh W. The role of ketoconazole in current prostate cancer care. Nat Rev Urol 2018; 15(10): 643-51.

10. Stuchbery R, McCoy PJ, Hovens CM, Corcoran NM. Androgen synthesis in prostate cancer: do all roads lead to Rome? Nat Rev
Urol 2017; 14(1): 49-58.

11. Qazi SM, Gul W. Trial without catheter with alpha blockers in acute urinary retention due to benign prostatic hyperplasia. Annals of PIMS ISSN. 2016; 1815: 2287.

12. Fitzpatrick JM, Kirby RS. Management of acute urinary retention. Br J Urol Int 2006; 97(s2): 16-20.

13. Agrawal MS, Yadav A, Yadav H, Singh AK, Lavania P, Jaiman R. A prospective randomized study comparing alfuzosin and tamsulosin in the management of patients suffering from acute urinary retention caused by benign prostatic hyperplasia. Indian J Urol 2009; 25(4): 474-78.

14. Hartung R. Do alpha-blockers prevent the occurrence of acute urinary retention? Eur Urol 2001; 39(1): 13(s6)-18.

15. Elbendary M, El-Gamal OM, Soliman MG, Tawfik A, Taha MR. Role of combined use of ketoconazole and tamsulosin in management of acute urinary retention due to benign prostatic obstruction (a randomized controlled trial). Prostate Cancer Prostatic Dis 2013; 16(4): 362-66.

16. Manikandan R, Srirangam SJ, O'Reilly PH, Collins GN. Management of acute urinary retention secondary to benign prostatic hyperplasia in the UK: A national survey. BJU Int 2004; 93(1): 84 88.

17. McNeill AS, Rizvi S, Byrne D. Prostate size influences the outcome after presenting with acute urinary retention Br J Urol Int 2004; 94(3): 559-62.

18. Shamim M, Idrees M, Bano S. Outcome of open prostatectomy. J Surg Pak Int 2012; 17(3): 87-92.

19. Djavan B, Madersbascher S, Klinger C, Marberger M. Urodynamic assessment of patients with acute urinary retention: is treatment failure after prostatectomy predictable? J Urol 1997; 158(5): 1829-33.

20. Reynard MJ, Shearer RJ. Failure to void after transurethral resection of prostate and mode of presentation. Urol 1999; 53(2): 336-39.

21. Milani S, Djavan B. Lower urinary tract symptoms suggestive of benign prostatic hyperplasia: latest update on alpha-adrenoceptor antagonists. Br J Urol Int 2005; 95(s4): 29-36.

22. Nordling J. Efficacy and safety of two doses (10 and $15 \mathrm{mg})$ of alfuzosin or tamsulosin $(0.4 \mathrm{mg})$ once daily for treating symptomatic benign prostatic hyperplasia. Br J Urol Int 2005; 95(7): 1006-12.

23. Dunn CJ, Matheson A, Faulds DM. Tamsulosin: a review of its pharmacology and therapeutic efficacy in the management of lower urinary tract symptoms. Drugs Aging 2002; 19(2): 135-61.

24. McNeill SA, Hargreave TB. Members of the alfaur study group. Alfuzosin once daily facilitates return to voiding in patients in acute urinary retention. J Urol 2004; 171(2): 2316-20. 